\title{
COMPARISON OF SENSITIVITY AND SPECIFICITY OF ALVARADO SCORE WITH MODIFIED ALVARADO SCORE IN PATIENTS WITH ACUTE APPENDICITIS: IN A TERTIARY CARE HOSPITAL RIMS, SRIKAKULAM
}

\author{
Prasada Rao Dasari1, Suraj Kumar Pattnayak2, Dharma Kishore Raja Chenna33, Jagadish Namballa 4 \\ ${ }^{1}$ Associate Professor, Department of Surgery, Rajiv Gandhi Institute of Medical Sciences, Srikakulam. \\ ${ }^{2}$ Assistant Professor, Department of Surgery, Rajiv Gandhi Institute of Medical Sciences, Srikakulam. \\ ${ }^{3}$ Assistant Professor, Department of Surgery, Rajiv Gandhi Institute of Medical Sciences, Srikakulam. \\ ${ }^{4}$ Assistant Professor, Department of Surgery, Rajiv Gandhi Institute of Medical Sciences, Srikakulam.
}

ABSTRACT
BACKGROUND
Acute Appendicitis is one of the commonest surgical emergencies. Despite advancement in diagnostic technology, diagnosis of
appendicitis is based on clinical suspicion leading sometimes to removal of normal appendix. Sometimes diagnosis is delayed till
complications like perforation, mass formation leading to increased mortality and morbidity; various scoring systems have been
evolved to make a diagnosis of appendicitis. Alvarado Scoring and Modified Alvarado Scoring system are widely used to identify the
patients needing appendicectomy.

\section{OBJECTIVES}

The aim of the study was to evaluate and compare the diagnostic validity of the modified Alvarado Score with the Alvarado Score for the diagnosis of acute appendicitis.

\section{MATERIALS AND METHODS}

A retrospective study of 78 patients admitted with abdominal pain in Rt. iliac fossa suggestive of appendicitis from January 2015 to April 2016 was conducted. Data including clinical signs and symptoms and laboratory findings were recorded in Alvarado Score and Modified Alvarado Score in the record form.

\section{INCLUSION CRITERIA}

All patients of age more than 12 years and less than 70 years with acute abdominal pain in Right iliac fossa presumed to be of appendicular origin

\section{EXCLUSION CRITERIA}

Patients with age less than 12 yrs. and more than 70 yrs. Patients with palpable mass on abdominal examination and with signs of peritonitis and patients who are not willing for surgery.

\section{RESULTS}

Out of the 78 hospitalised patients 71 patients had an appendicectomy, of these 2 did not have acute appendicitis. In 71 patients who underwent operation those with an Alvarado Score of 9 to 10 were almost certain to have appendicitis, had a sensitivity of $48 \%$ and specificity of $100 \%$. Those with a score of 7-8 (which had a high likelihood of appendicitis had a sensitivity of $48 \%$ and specificity of $100 \%$ ). For the modified Alvarado Score, those with a score of 9 to 10 had a sensitivity of $57.7 \%$ and specificity of $100 \%$. Those with a score of 7-8 had a sensitivity of $98 \%$ and specificity of $90 \%$ respectively. The positive predictive values and accuracy of left shift were $94 \%$ and $61.4 \%$ in Alvarado Score. For extra sign (cough test, Rovsing's sign and rectal tenderness), the figures were $94.7 \%$ and $83.3 \%$ respectively.

\section{CONCLUSION}

In the diagnosis of acute appendicitis the Alvarado Score and Modified Alvarado Score are a fast, simple, reliable, non-invasive scoring system, repeatable and safe diagnostic modality without extra expenses and complications. This study showed that accuracy of Modified Alvarado Score was slightly higher than the Alvarado Score in diagnosing appendicitis.

\section{KEYWORDS}

Alvarado Score, Modified Alvarado Score, Appendicitis.

HOW TO CITE THIS ARTICLE: Dasari PR, Pattnayak SK, Chenna DKR, et al. Comparison of sensitivity and specificity of Alvarado score with modified Alvarado score in patients with acute appendicitis: in a tertiary care hospital RIMS, Srikakulam. J. Evolution Med. Dent. Sci. 2016;5(72):5277-5280, DOI: 10.14260/jemds/2016/1196

Financial or Other, Competing Interest: None.

Submission 18-08-2016, Peer Review 29-08-2016,

Acceptance 01-09-2016, Published 07-09-2016.

Corresponding Author:

Dr. Prasada Rao Dasari

Associate Professor, Department of Surgery,

RIMS, Srikakulam-532001, Andhra Pradesh

E-mail: prasadrao.dasari@gmail.com

DOI: $10.14260 /$ jemds/2016/1196

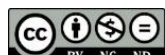

\section{INTRODUCTION}

Acute appendicitis is the commonest surgical emergency(1) worldwide. Incidence is 1.17 per 1000 population and lifetime risk is $8.6 \%$ among males and $6.7 \%$ in females.(2) The incidences are more in adolescents and young adults, but incidence of complications shows little variation in the age group.(3)

Classical signs and symptoms of acute appendicitis were first described by Reginald Heber Fitz in 1886.(4) Typical cases 
present with paraumbilical pain migrating to right iliac fossa nausea, vomiting and fever. Variation in position of Appendix, age of patient, degree of inflammation makes the clinical presentation inconsistent.

Failure to make an early diagnosis may lead to the risk of perforation and complications. The complication rate in nonperforative appendicitis is $1 \%$, but it is as high as $5 \%$ or more in young and elderly patients in whom the diagnosis is delayed.(4) Various scoring systems have been evolved to make the diagnosis of acute appendicitis. Popular among them is Alvarado Score described in 1986.(5)

The classical Alvarado Score includes left shift of neutrophil maturation, which is not routinely done in laboratories. Kalam et al omitted left shift of neutrophil in modified Alvarado Score, which includes extra sign (eg. Cough test, Rovsing's signs and rectal tenderness) are helpful in minimising unnecessary appendectomy and is practical and reliable and easily done. Some studies demonstrated that extra sign had a sensitivity of $71 \%$ and specificity of $68 \%$. The aim of the study is to compare the diagnostic validity of Alvarado Score to the Modified Alvarado Score.

\section{MATERIALS AND METHODS}

This is a retrospective study of 78 patients admitted with abdominal pain in right iliac fossa suggestive of acute appendicitis from January 2015 to April 2016 at Rajeev Gandhi Institute of Medical Sciences, Srikakulam, Andhra Pradesh.

Data including Age, Sex, Symptoms, Physical Signs and Laboratory findings such as white blood count and differential count were recorded in Alvarado and Modified Alvarado Score form (Table 1, 2).6,7 Table 1 and 2 test the eight specific indicators. Patients with a score of $>9$ are almost certain to have appendicitis and those with a score of 5-6 are compatible with but not diagnostic of appendicitis. Score of $<4$ are unlikely to have appendicitis.

\begin{tabular}{|c|c|c|c|}
\hline & & Score & Yes/No \\
\hline \multirow[t]{3}{*}{ Symp } & $\begin{array}{l}\text { Migratory pain (Pain } \\
\text { migrating from umbilicus to Rt } \\
\text { iliac fossa) }\end{array}$ & 1 & \\
\hline & Anorexia & 1 & \\
\hline & Nausea/Vomiting & 1 & \\
\hline \multirow{3}{*}{ Sign } & Rt Lower quadrant pain & 2 & \\
\hline & Rebound tenderness & 1 & \\
\hline & Elevation of temperature & 1 & \\
\hline \multirow{2}{*}{ Lab } & Leucocytosis & 2 & \\
\hline & Left Shift & 1 & \\
\hline Total & & 10 & \\
\hline
\end{tabular}

\begin{tabular}{|c|c|c|c|}
\hline & & Score & Yes/No \\
\hline \multirow[t]{3}{*}{ Symp } & $\begin{array}{l}\text { Migratory pain (Pain } \\
\text { migrating from umbilicus } \\
\text { to Rt iliac fossa) }\end{array}$ & 1 & \\
\hline & Anorexia & 1 & \\
\hline & Nausea/Vomiting & 1 & \\
\hline \multirow{4}{*}{ Sign } & Rt Lower quadrant pain & 2 & \\
\hline & Rebound tenderness & 1 & \\
\hline & Elevation of temperature & 1 & \\
\hline & Extra sign (cough test) & 1 & \\
\hline \multirow[t]{2}{*}{ Lab } & $\begin{array}{l}\text { Rovsing's sign and rectal } \\
\text { tenderness }\end{array}$ & 1 & \\
\hline & Left Shift & 2 & \\
\hline Total & & 11 & \\
\hline \multicolumn{4}{|c|}{ Table 2: Modified Alvarado Score } \\
\hline
\end{tabular}

All patients were retrospectively evaluated and scored on the admission sheet. The Alvarado score and Modified Alvarado score played no role in the management of these patients. The diagnosis of acute appendicitis was made clinically by the surgical team (Residents and Specialists). The scores were subsequently correlated with the clinical, operative and histopathological finding.

\section{RESULTS}

Of the 78 patients admitted, 7 (8.5\%) patients were kept for observation and treated conservatively. They were discharged with diagnostic of other than appendicitis. Of the 78 patients 71 patients (92\%) had appendicectomy, of these 2 patients (2.5\%) did not have acute appendicitis, one of them showed signs of PID and the other one having UTI.

\section{Of the 78 Patients who had Acute Appendicitis}

$\begin{array}{lll}\text { Males } & : & 49(63 \%) \\ \text { Females } & : & 29(37 \%) \\ \text { Mean age in Males } & : & 25(10 \text { to } 50 \text { yrs. }) \\ \text { Females } & : & 19(14 \text { to } 47 \text { yrs.) }\end{array}$

The pathological study in 71 patients who underwent appendicectomy were analysed in Table 3 . The total score of 78 patients who had acute abdominal pain suggestive of acute appendicitis were recorded in score form and are summarised in each score range (Table 4).

\begin{tabular}{|c|c|c|}
\hline \multicolumn{2}{|c|}{ Patients with Score of 9-10 are Certain } \\
to have Appendicitis \\
\hline & Sensitivity & Specificity \\
\hline $\begin{array}{c}\text { Alvarado Scoring } \\
\text { System }\end{array}$ & $50 \%$ & $100 \%$ \\
\hline $\begin{array}{c}\text { Modified } \\
\text { Alvarado Scoring } \\
\text { System }\end{array}$ & $59 \%$ & $100 \%$ \\
\hline
\end{tabular}

\begin{tabular}{|c|c|c|}
\hline \multicolumn{3}{|c|}{ Pts. with a Score of 7 to 8 } \\
\hline & Sensitivity & Specificity \\
\hline $\begin{array}{c}\text { Alvarado Scoring } \\
\text { System }\end{array}$ & $90 \%$ & $98 \%$ \\
\hline $\begin{array}{c}\text { Modified } \\
\text { Alvarado } \\
\text { Scoring System }\end{array}$ & $98 \%$ & $98 \%$ \\
\hline
\end{tabular}

The evaluation of Clinical and Laboratory findings in acute appendicitis were listed in (Table 5); a differential white cell count with a shift to the left and extra signs were useful indicators in acute appendicitis, as they have good predictive value $(94.1 \%)$ and $94.7 \%$. Extra signs showed greater sensitivity and accuracy than left shift. However, specificity of extra sign and left shift were poor, $50 \%$ and $60 \%$.

\begin{tabular}{|c|c|c|}
\hline Stage & No. & Percentage \\
\hline Inflammation & 34 & $48 \%$ \\
\hline Suppurative & 14 & $19.7 \%$ \\
\hline Gangrenous & 8 & $11.9 \%$ \\
\hline Perforation & 15 & $21.1 \%$ \\
\hline \multicolumn{2}{|c|}{ Table 3: Pathological Stage of Acute Appendicitis } \\
\hline
\end{tabular}




\begin{tabular}{|c|c|c|c|c|}
\hline \multirow{2}{*}{$\begin{array}{c}\text { Range } \\
\text { Score }\end{array}$} & \multicolumn{2}{|c|}{ Alvarado Score } & \multicolumn{2}{c|}{ Modified Alvarado } \\
\cline { 2 - 5 } & Appendicitis & $\begin{array}{c}\text { Other } \\
\text { Diseases }\end{array}$ & Appendicitis & $\begin{array}{c}\text { Other } \\
\text { Diseases }\end{array}$ \\
\hline $0-4$ & 1 & 0 & 1 & 0 \\
\hline $5-6$ & 1 & 6 & 1 & 6 \\
\hline $7-8$ & 34 & 1 & 26 & 0 \\
\hline $9-10$ & 35 & 0 & 43 & 0 \\
\hline Table 4: The Last Total Score of 78 Patients who were \\
Admitted with Acute Abdominal Pain Suggestive of Acute \\
Appendicitis Alvarado, Modified Alvarado \\
\hline
\end{tabular}

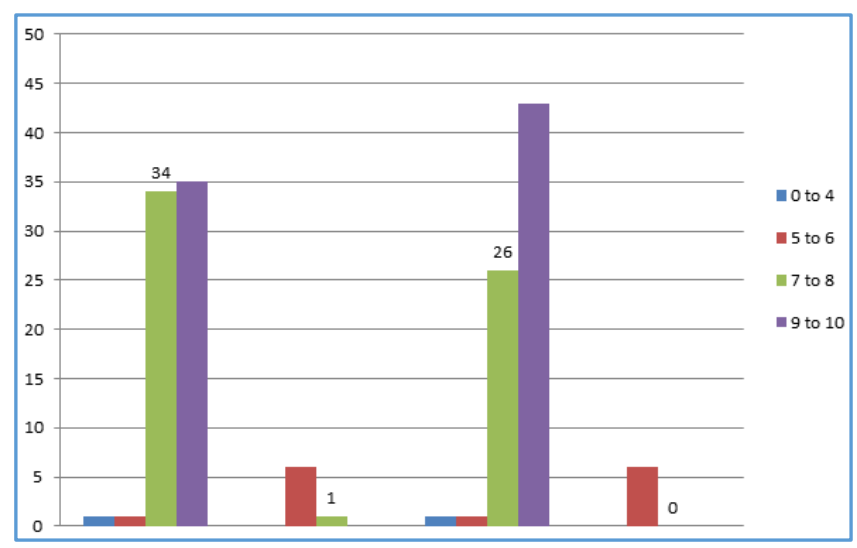

Table 5: Alvarado Score, Modified Alvarado Score

\begin{tabular}{|c|c|c|c|c|c|}
\hline & \multirow[t]{2}{*}{ 竭 } & \multirow[t]{2}{*}{$\begin{array}{l}\frac{\vec{z}}{\pi} \\
\frac{\pi}{0} \\
\text { क }\end{array}$} & \multicolumn{2}{|c|}{ 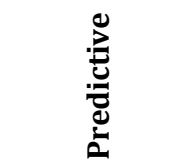 } & \multirow[t]{2}{*}{ 冚 } \\
\hline & & & +ve & -ve & \\
\hline $\begin{array}{l}\text { Migration of } \\
\text { Pain }\end{array}$ & 76.9 & 50.0 & 0.94 & 0.17 & 74.6 \\
\hline Anorexia & 86.5 & 70.0 & 0.96 & 0.37 & 86.8 \\
\hline $\begin{array}{c}\text { Nausea, } \\
\text { Vomiting }\end{array}$ & 86.8 & 40.0 & 0.93 & 0.21 & 81.3 \\
\hline RLQ Pain & 100 & 10.0 & 0.92 & 1 & 92.1 \\
\hline $\begin{array}{c}\text { Rebound } \\
\text { Tenderness }\end{array}$ & 86.5 & 50.0 & 0.94 & 0.26 & 83.3 \\
\hline $\begin{array}{c}\text { Elevation of } \\
\text { Tempered } \\
>37.5 \\
\end{array}$ & 60.6 & 70.0 & 0.95 & 0.15 & 61.4 \\
\hline Leukocytosis & 89.4 & 30.0 & 0.93 & 0.21 & 84.2 \\
\hline Left Shift* & 61.5 & 60.0 & 0.94 & 0.13 & 61.4 \\
\hline Extra Sign * & 86.5 & 50.0 & 0.94 & 0.26 & 83.3 \\
\hline
\end{tabular}

*Left Shift, Differential White Cell Count with shift to left (neutrophil more than normal range)

*Extra Sign - Cough test, Rovsing and Rectal tenderness

\section{DISCUSSION}

The clinical diagnosis of acute appendicitis continues to be difficult in some patients due to variable presentation of the disease and lack of reliable diagnostic test.

In the past few years, various scoring systems have been evolved to help in making the diagnosis of acute appendicitis. Alvarado scoring system is a simple scoring system, helps in diagnosing Appendicitis. It is devised by giving relative weight to specific clinical symptoms and signs and laboratory findings. Patients with scoring of 9 and 10 are almost certain to have appendicitis and to be operated. Patients with a scoring 7-8 have a high likelihood of appendicitis, while a score 5 to 6 indicates probability of appendicitis but is not diagnostic of it. CT scoring is certainly appropriate to patients with Alvarado scoring of 5-6. With a scoring of 0 to 4 it is difficult to justify the expense, radiation exposure time and possible complications of CT scanning. It is extremely unlikely for these patients to have appendicitis.

In a prospective study of 215 adults and children in Cardiff, the use of Alvarado score decreased in unusually high false positive appendicectomy rates of $44 \%$ to $14 \% .{ }^{8}$ Fengo et al reported a sensitivity of $90.2 \%$ and specificity of $91.4 \%$ and others reported a sensitivity of $73 \%$, specificity of $87 \%$ with a negative laboratory ratio of $17.5 \% .{ }^{9}$ To be useful, a scoring system must be both sensitive as well as specific. Our study showed that modified Alvarado score is effective in making a diagnosis of acute appendicitis and is practicable. The extra signs were more accurate and alone by the attending clinician, whereas left shift is a laboratory finding. All patients suspected to be having appendicitis should be evaluated for extra sign, because anatomical variation in position of the inflamed appendix is misleading. Cough test and Rovsing's sign also indicates peritoneal irritation. The diagnosis of acute appendicitis is difficult in women, because of the presence of gynaecological disorders.

A pelvic examination is essential, which may reveal the missing information. A rectal examination does not appear to be a reliable element in the diagnosis of acute appendicitis, because of its low diagnostic weight.

However, there is no clinical scoring system that gives $100 \%$ certainty. We can use the diagnostic score as a guide to decide if the patient needs observation or surgery. Patients with score 5-6 can be observed and monitored every four to six hours. If the score increases, patients may need laparotomy. If it is difficult to ascertain, CT scan is needed in making diagnosis. Patients with score of 7 and above require surgery.

\section{CONCLUSION}

Ours is retrospective study and our results are similar to the other prospective studies. $(10,11,12)$ The modified Alvarado score and the Alvarado score are useful complimentary methods in the diagnosis of patients suspected to have acute appendicitis. The diagnostic value of the Modified Alvarado score is slightly higher than the Alvarado score in this study.

\section{REFERENCES}

1. Brahmachari S, Jajee AB. Alvarado score: a valuable clinical tool for diagnosis acute appendicitis-a retrospective study. J Med Allied Sci 2013;3(2):63-66.

2. Addiss DG, Shaffer N, Fowler BS, et al. The epidemiology of appendicitis and apendectomy in United States. Am J Epidemiol 1990;132(5):910-925.

3. Korner H, Söndenaa K, Söreide JA, et al. Incidence of acute non perforated and perforated appendicitis: age-specific and sex-specific analysis. world J Surg 1997;21(3): 313-317.

4. Fitz RH. Perforating inflammation of the vermiform appendix with special reference to its early diagnosis and treatmanet. Am J Med Sci 1886;92:321-46.

5. Alvarado A. A practical score for the early diagnosis of acute appendicitis in emergency. Ann Emerg Med 1986;15 (5):557-64. 
6. Bernardm, Berger J, Berger DH. The appendix. Schwartz principles of surgery. 8th edn. New York: McGraw-Hill 2005:p.1119-38.

7. Al-Fallouji MAR. Clinical surgery in general. Postgraduate surgery. 7th edn. The candidate's guide1999:p. 383-9.

8. Owen TD, Williams H, Stiff G, et al. Evaluation of the alvarado score in acute appendicitis. J R Soc Med 1992;85(2):87-8.

9. Fenyo G, Lindberg G, Blind $\mathrm{P}$, et al. Diagnostic decision support in suspected acute appendicitis: validation of simplified scoring system. Eur J Surg 1997;163:831-8.
10. Talukder DB, Siddiq AKMZ. Modified alvarado scoring system in the diagnosis of acute appendicitis. JAFMC Bangladesh 2009;5(1):18-20.

11. Maral FT, Ansari HMA, Kamoona BR. Evaluation of modified alvarado score in the diagnosis of acute appendicitis at Baghdad teaching hospital. The Iraqi Post Graduate Medical Journal 2012;11:675-83.

12. Mahato IP, Bhandari R, Rajbhandari R, et al. Sensitivity and specificity of clinical features used in alvarado scoring system. Health Renaissance 2011;9(1):12-14. 